Provided by the author(s) and University of Galway in accordance with publisher policies. Please cite the published version when available.

\begin{tabular}{|c|l|}
\hline Title & Knowledge sharing in a collaborative networked environment \\
\hline Author(s) & Cormican, Kathryn \\
\hline $\begin{array}{c}\text { Publication } \\
\text { Date }\end{array}$ & 2007 \\
\hline $\begin{array}{c}\text { Publication } \\
\text { Information }\end{array}$ & $\begin{array}{l}\text { Cormican, K. and Dooley, L. (2007) 'Knowledge sharing in a } \\
\text { and Knowledge Management, 16 (2):105-115. }\end{array}$ \\
\hline $\begin{array}{c}\text { Link to } \\
\text { publisher's } \\
\text { version }\end{array}$ & http://dx.doi.org/10.1142/S0219649207001706 \\
\hline $\begin{array}{c}\text { Item record } \\
\text { hermation }\end{array}$ & http://hdl.handle.net/10379/3706 \\
\hline
\end{tabular}

Downloaded 2023-04-26T15:07:59Z

Some rights reserved. For more information, please see the item record link above. 
Cormican, K. and Dooley, L. (2007) Knowledge sharing in a collaborative networked environment, Journal of Information and Knowledge Management, 16, 2, 105-115.

\title{
Knowledge Sharing in a Collaborative Networked Environment
}

\author{
Kathryn Cormican ${ }^{1}$ and Lawrence Dooley* \\ CIMRU, Industrial Engineering, National University of Ireland, Galway, Ireland \\ Tel: + 35391512292 \\ Fax: + 35391562894 \\ Email: Kathryn.Cormican@nuigalway.ie \\ *Department of Management and Marketing, O'Rathilly Building, University \\ College Cork, Ireland \\ Tel: + 353214903027 \\ Email: I.dooley@ucc.ie,
}

\begin{abstract}
Knowledge is a key resource that must be managed within organisations and across collaborative enterprise networks. In particular, the two major challenges that face such organisations are; ensuring that they have the appropriate knowledge to support their operations and ensuring that they optimise these knowledge resources available to them. In recent years, researchers, consultants and industrialists have developed approaches in an attempt to address these requirements. Most of these approaches have been technology oriented. In other words, the implementation of information technology systems is seen as the solution to enterprise knowledge management problems. However, research indicates that organisations are still failing to convert individual skills and competencies into tangible products and services. Knowledge management is an emerging discipline and it is still not very well understood or managed in industry. Consequently, new knowledge initiatives are not exploited to their full potential. In other words, companies are not reaping the full benefits of knowledge management projects. This paper explores the key constituents to managing knowledge and examines the main problems with sharing knowledge across teams and organisational boundaries. Findings from a qualitative study suggest that the
\end{abstract}

\footnotetext{
${ }^{1}$ Corresponding Author
} 
key problems to managing knowledge across a collaborative network are person centric and consequently managers should focus their efforts on improving critical areas such as motivation and trust as well as people oriented methods and tools.

Keywords: Enterprise knowledge management, knowledge sharing, problems and challenges, exploratory study

\section{Introduction}

The competitiveness and sustainability of a modern organisation depends on its ability to behave in an entrepreneurial manner and innovate successfully. Innovation is a continuous and cross-functional process involving and integrating a growing number of different competencies inside and outside the organisation's boundaries. Astute organisations are reconfiguring their business systems to promote these external linkages in order to innovate successfully. Consequently the balance of work is moving from stable, physically collocated functions to dynamic, competency-based, business networks (Voss, 2003; Walters, and Buchanan, 2001; Wright, and Burns, 1998). Networks link organisations, customers and suppliers to create virtual organisations in order to exploit emerging opportunities (Cormican and O'Sullivan, 2004; Venkatraman and Henderson, 1998). They generate value by synthesising information and knowledge across traditional boundaries in order to create new products and services and achieve innovations outside of their individual capabilities (Prasad and Akhilesh, 2002; Johnson et al, 2001; Ratcheva and Vyakarnam, 2001; Pawar and Sharifi, 2000). Ideally, networks share critical information and knowledge, exploit expertise and pool resources for the collective benefit. They allow organisations to focus scarce resources where they possess real competencies and they also enable them to acquire other capabilities that they lack from the marketplace (Richardson, 1995). In this modern era competition is no longer between individual organisations but instead between networks. Therefore managing an organisation's knowledge assets across a network and converting it into commercially successful products and services through effective collaboration is fast becoming a critical component of competitive success. 
Drucker (1993) notes that "knowledge is the only meaningful resource today" and adds that, "the traditional factors of production have become secondary, they can be obtained easily, provided there is knowledge". In this view, the generation and implementation of new knowledge is fast becoming the only remaining sustainable source of competitive advantage for first world organisations. A company's success depends on making the most of its collective knowledge and that means supporting the people and the processes required to accumulate, structure, and transfer knowledge effectively. Having immediate access to the latest information including information from external sources can provide a critical competitive edge. This is a view supported by other researchers (Harris, 1999; Gunasekaran, 1999; Sveiby, 1997; Davenport et al, 1996). According to Knock et al (1997), "the single most important factor that ultimately defines the competitiveness of an organisation is its ability to acquire, evaluate, store, use and discard knowledge and information". Thus knowledge is a key resource that must be managed if innovative efforts are to succeed and businesses are to remain competitive in global markets.

Effective knowledge generation and transfer are replacing manual skills as the organisational basis for adding value (Wilson, 1996). This is depicted in the new, virtual value chain which views Porter's physical value chain (see Porter, 1985) being replaced by the intangible activities of the virtual value chain (Rayport and Sviokla, 1995). Knowledge is a transferable unit, whose value is enhanced when it satisfies a practical need in a timely, cost effective manner. Therefore, organisations and the networks within which they operate must manage their knowledge effectively in order to gain competitive advantage (Gunasekaran, 1999; Balasubramaniam and Tiwana, 1999; Davenport and Prusak, 1998; Nonaka and Takeuchi, 1995; Stewart, 1997; Grant, 1997; Pan and Scarbrough, 1998). This advantage can be realised in outputs such as opening new markets, more innovative designs, faster development times, reduced cost, creation of ancillary intellectual property and even a more robust network. 
Thus, it is critical to their future success that organisations focus attention on how knowledge may be optimised and exploited across enterprise networks. However this process is intricate and complex and is difficult to manage (Cormican and O'Sullivan, 2003a; Jaffe, 1989; Balconi et al., 2004). To date many of the proposed solutions to knowledge management are technology driven and focus on managing existing knowledge (Nonaka and Takeuchi, 1995; Warner and Witzel, 2004). In other words, information technology oriented applications such as decision support systems, expert systems, and groupware systems are seen as the key to solve knowledge management problems. However, a significant quantity of an organisation's knowledge is personal and only resides in the minds of employees (Nonaka and Takeuchi 1995). Research indicates that existing enterprise knowledge management approaches and systems are not effective since knowledge does not flow seamlessly between individuals and network nodes (Wiig, 1995). As a consequence, many organisational networks encounter situations where knowledge sharing is impeded, learning opportunities missed and innovations remain unexploited (Kruat et al., 1990; Kiesler and Cummings, 2002).

Knowledge must be explicated and separated from the knowledge workers, so that the critical knowledge is trapped and not forgotten (Tidd, 2001; Kreiner, 2002). To this end organisations must seek to transform employees' tacit knowledge into a collective asset that is owned by the entire network and improve the processes by which knowledge is shared and exploited (Warkentin et al, 2001; Hildreth, 2000). Leaders must facilitate a culture of collaboration and knowledge sharing across the network (Cormican and O'Sullivan, 2003b; Dooley and O'Sullivan, 2003; Hussler and Ronde, 2002). They must also address potential conflicts that may exist between the desire to protect the organisations intellectual competitive advantage from their competitors and the need to share this knowledge freely within the network, which may contain past competitors. This paper seeks to examine knowledge sharing within the context of a collaborative environment and attempts to address the key issues constraining its development. The goal of our research is to provide a better understanding of the dynamics of knowledge sharing within collaborative networks. It aims to help researchers and practitioners 
effectively manage organisational knowledge and enhance the effectiveness of their collaborative networks. The paper seeks to define and classify knowledge. It highlights problems associated with sharing knowledge across collaborative networks. It also explores the human and technical dimensions to knowledge management. The remainder of the paper focuses on identifying the critical impediments to knowledge sharing both within and across organisational boundaries. The results of a qualitative study are presented and discussed. By understanding where the impediments to effective knowledge sharing exist, practitioners can focus their efforts on avoiding the pitfalls and thus facilitate effective knowledge exchange and exploitation. 


\section{Understanding Organisational Knowledge}

\subsection{Defining Knowledge}

Knowledge is an elusive concept and therefore it is important to define it in context in order to understand it. The term is used in several different ways in the literature. For example, Nonaka and Takuechi (1995) two of the early researchers in this field adopt a philosophical angle and define knowledge as "justified true belief". In this view, knowledge is an opinion, idea or theory that has been verified empirically and agreed upon by a community. According to Wilson (1996), knowledge at the most basic level is "that which is known". Quinn et al (1996) associate knowledge with professional intellect, where professional intellect in organisations' focus on know-what, know-why, knowhow and self motivated creativity. Stewart (1997) also considers knowledge in terms of intellectual capital. On the other hand, Bohn (1994) examines knowledge in terms of a company's processes. He believes that an organisation's knowledge about its processes may range from total ignorance about how they work to very complex and formal mathematical models. According to Davenport et al (1998), knowledge is information combined with experience, context, interpretation and reflection. It is a high value form of information that is ready to apply to decisions and actions. Knowledge can be defined as the integration of ideas, experience, intuition, assertions, skills and lessons learned that have the potential to create value for a business by informing decisions and improving performance. In this view, knowledge is a key enabler to organisational success. However, in order for knowledge to be useful it must be available, accurate, effective and accessible.

\subsection{Classifying Knowledge}

Many types of knowledge have been suggested in the literature. These are summarised in table 1 . This list is not exhaustive but it does provide some indication of the intricacy of the topic. Considerable attention has been paid to the distinction between explicit (codified) knowledge and tacit (implicit) knowledge (Kreiner, 2002; Hildreth et al, 2000; Haldin-Herrgard, 2000; Grant, 1996). Explicit or codified knowledge refers to knowledge that can be communicated in a formal or systematic language. Such knowledge can be 
captured in formulae, designs, manuals or books and it is normally easy to share. The term tacit knowledge was originally coined by Polanyi (1966) and is personal knowledge, consisting of highly subjective insights, intuitions and instincts (Wilson, 1996). Tacit knowledge has a personal quality that makes it hard to formalise and communicate. It is obtained by internal individual processes like experience, reflection, or individual talents, deeply rooted in action and involved in a specific context.

Many researchers note that that tacit knowledge is difficult to articulate and share (Haldin-Herrgard, 2000; Zack, 1999; Bennett and Gabriel, 1999) However it is also argued that it is tacit rather than explicit knowledge that is typically more valuable to organisations (Nonaka and Konno, 1998; Leonard and Sensiper, 1998; Holthouse, 1998).

\section{Classification}

Tacit knowledge

Explicit knowledge

Migratory knowledge

Embedded knowledge

Experiential knowledge

Reported knowledge

Intimate knowledge

Declared knowledge

Cognitive knowledge

Advanced skills

Systems understanding

Self motivated creativity

Process knowledge

Factual knowledge

Catalogue knowledge

Cultural knowledge
Description

Implicit, personal knowledge

Codified knowledge, can be communicated

Shared knowledge, can move

Cannot be separated knowledge from an entity

Knowledge that is pragmatic and practical

Knowledge that is published or disclosed

Knowledge that is deep seated or experienced

Knowledge that is professed or purported

Know what something is about

Know how to do something

Stewart (1997)

Know why something should be done

Care why something should be done

Methods for doing things well

Basic information about people and things

Reported By

Polanyi (1966)

Badaracco (1991)

Wikstrom et al (1994)

Knowing where things are

Understanding values, rules and norms

Table 1 Classification of Knowledge Types

Many of the problems associated with knowledge management relate to its lack of an absolute definition. For example, many computer scientists define knowledge management in terms of understanding the relationships of data, 
identifying and documenting rules for managing data and assuring that data are accurate and integrity is maintained (Davies et al, 2003). On the other hand other researchers propose a community or social-based model of knowledge management (Kreiner, 2002; Blackler, 1995). They believe that interpreting knowledge in terms of rules and procedures embedded in technology does not take into consideration critical elements such as emotions, values or instincts. The social model implies that knowledge is "embedded in and constructed from and through social relationships and interactions" and is "achieved through shared understandings and attitudes" (Scarborough and Swan, 1999). Sharing and exchange of knowledge across organisational boundaries is seen as the key to the effective exploitation of knowledge (Gibbons et al, 1994) and sustainability of the collaborative network.

\subsection{Sharing Knowledge}

Knowledge sharing and collaboration facilitate the cross fertilisation of ideas and enhanced creativity (Cormican and O'Sullivan, 2003b; West et al, 1997). According to Jones and Jordan (1998), knowledge sharing and exchange depends on personal networks and the willingness of individuals to participate in the process. A great deal of what people learn and therefore what the organisation comes to know, results from personal interaction (Ruggles, 1998; Ulrich, 1998). Organisations leverage individual talents into collective achievements through collaborative networks. Consequently, organisational reporting lines and structures are being reorganised not around traditional tasks or functional departments, but around these communities of practice. Collaborative networks are self-directed groups of people, bound together by a common mission and passion for a joint enterprise (Wegner, 1998). These networks are not only mechanisms for communicating they also help to advance collective understanding by providing a forum for sense making. In doing so, they create value for their individual members as well as the organisation. They are organic networks in the sense that they evolve as a result of the informal interaction of the members over time as the knowledge base evolves as well. Organisations that create an environment that supports their formation are gaining significant benefits in the areas of knowledge 
transfer, response times and innovation (Warkentin et al, 2001; Hildreth, 2000; Wegner, 1998; Brown and Duguid, 1991). Thus organisations can create synergies by enabling network participants to build on each other's ideas, deepen their thinking and understanding and ultimately result in more effective innovation.

A fundamental problem that inhibits effective knowledge sharing and integration across networks is 'distance' between the stakeholders, in particular geographic and cognitive distance (Balconi et al., 2004). Numerous researchers have suggested that physical distance between network stakeholders can seriously impact on the success of collaborative efforts (Kruat et al., 1990; Kiesler and Cummings, 2002). It has been noted in relation to academic-industry collaboration, that scientific and technical knowledge is often tacit and uncodifiable, and so close geographic proximity between the partners is necessary (Jaffe, 1989; Balconi et al., 2004). The issue of cognitive distance between the various network stakeholders can also seriously impede effective knowledge integration (Balconi et al, 2004). Different outlooks and mindsets of stakeholders engaged in collaboration can also result in misunderstanding and disagreement since "their ideas and behaviour are grounded on different tacit and codified knowledge stocks, [and] also their incentives and motivation differ" (Hussler and Ronde, 2002). Thus in order to achieve cognitive proximity, significant cultural movement on the part of all stakeholders is required (Currall, 2003). In fact, Hussler and Ronde (2002) suggests that while geographic and cognitive distance may in fact be substitutes, "geographic proximity is not needed within cognitive communities" and hence achieving cognitive proximity may be of highest priority

It has been proposed that geographic distance is becoming less of an impediment to distributed innovation and diverse collaboration as a consequence of information communication technology (ICT) developments (including email, intranets and e-groups). These new developments provide a ready infrastructure for sharing knowledge and experience between disparate entities (Finholt, 2002). They enable communication, enhance social networks 
and promote strategic knowledge exchange in order to achieve mutually beneficial objectives (Warkentin et al, 2001; Mandviwalla and Khan, 1999; Nadler and Tushman, 1999). However, technology alone cannot overcome the problems of geographic distance between stakeholders since "distance sensitive transmission means exchange mechanisms such as face-to-face clarifying discussions and on-site demonstrations" are often necessary to achieve integration (Balconi et al., 2004). ICT must be considered as a mere tool to facilitate the process and if the human element is ignored knowledge integration will not occur (Cormican and O'Sullivan, 2003a; Dooley and O'Sullivan, 2003; Hussler and Ronde, 2002).

\section{Methodology}

In order to identify where the barriers currently exist with respect to knowledge sharing in a collaborative environment, a study was undertaken using focused workshop techniques. The workshop was targeted at European researchers and industry leaders who collaborate on large and complex research projects and operate in a knowledge intensive environment. A total of 19 experts participated in the workshop, consisting of management consultants, research and development managers and academic researchers representing seven European countries and five individual projects. The aim of the workshop was not to focus on the specifics of the projects but instead to identify and prioritise the current problems and future challenges associated with sharing knowledge across a collaborative network environment. A socio-technical systems approach of analysing both hard (information technology infrastructure and enabling technologies) and soft (culture, beliefs and management of people) issues was undertaken, utilising a hands-on participative approach to illicit the key barriers to effective knowledge sharing and integration.

The primary research mechanism used to organise and correlate the workshop output was nominal group techniques. Nominal group techniques provide a reliable structure for a group discussion (see Langford, et al 2002, McDaniel and Gates, 2001, 2000, Oakland, 2000, de Ruyter, 1996). This method is particularly useful when (a) the issues that surrounding the problem 
appear large and complex, (b) the information relevant to the problem appears in unorganised thoughts and ideas and finally (c) where group consensus is required (or desired). This approach is an effective use of both time and effort and also facilitates the cross fertilisation of ideas. During the workshop each team member, in turn, identified key barriers to knowledge sharing and transfer across organisations in a network. Participants were then invited to reflect and record their suggestions on paper. Team members then discussed the merits of each item. Further discussions for the purpose of clarification also took place. Each item was then reviewed and duplications were eliminated by the facilitator who also ensured that all suggestions were clearly understood by all participants. Individual barriers were then grouped into related categories. The grouping helped to develop a common understanding of the problem. A voting procedure was used to rank all categories in order of priority. Here each participant was asked to select the top three items that (s)he considered to be the most important and rank them in order of priority. To do this they were each given three votes; one had a value of three points, the second had a value of two points and the third had a value of one point. They then assigned scores of three, two and one in order of importance to the categories they felt were the key barriers to knowledge sharing. Finally, the results were compiled and each category was assigned an aggregate score on the basis of the individual scores.

\section{Findings}

While it is apparent that there are many factors that facilitate and thus impede effective knowledge transfer across organisations some issues came to the fore by mutual consensus (see Table 2). These include (in order of importance) (a) motivation and skills, (b) trust (c) method and tools (d) resources and finally (e) information capture and access. These categories are not exclusive or exhaustive but rather blended and interlinked. They are discussed in more detail below. 

Lack of clarity of purpose at operational level Fear of loss of power if knowledge is shared

Fear to invest in the networks long-term value added at the expense of short-term benefit for the individual organisational node

Context-specific knowledge sharing values is not encouraged

Inadequate management competencies to prepare the organisation for knowledge management

Knowledge sharing not recognised or rewarded by node organisations

Difficulty understanding and negotiating with various personalities and cultures across the network

Insufficient ability to listen and empathise with others

Trust Lack of trust between individuals within the organisational node and across the network

Individuals are afraid of sharing proprietary information

Resistance to change

Methodology and Tools

Resources
Information
Capture and Access
10 Points

No additional resources allocates to organisation or network

Too much information is captured

2 Points
Tools are too generic and do not align with the context specific needs of the organisation or network

Tools available are not sufficiently user friendly

Lack of criteria for evaluating the relevance and appropriateness of knowledge management tools

No clear methodology for efficient and effective knowledge exchange across the network.

Technology is not person centric

Difficult to capture and classify information for others use

Information is often not stored in the correct format to facilitate sharing 


\subsection{Motivation and skills}

Motivation and skills was identified and ranked as the most important challenge for effective knowledge sharing across organisations in a network. According the findings of our workshop many participants who participated in inter firm collaboration are often unclear about the rationale and associated benefits. In other words, they are uncertain about the drivers, goals, advantages, rewards and returns for sharing information and knowledge with others. This makes it difficult for leaders to initiate successful inter firm collaboration. Furthermore, many participants feel that their employees and colleagues are not equipped with the appropriate skills for sharing knowledge. In other words, they are uncertain as to what information and knowledge to share and the format in which it could or should be transferred. Therefore, unless mutual benefits to collaboration are established and communicated to all parties from the outset, people will remain unwilling to participate and reluctant to learn new procedures for information exchange. The establishment of clear goals provides the form and focus for knowledge generation and transfer. Long term goal clarity is achieved when all employees know where the organisation is attempting to go in the future and why knowledge transfer is important to get there. Short-term goal clarity is achieved when managers set tangible and measurable goals for employees' work, which are in alignment with the overall goals of the organisation.

\subsection{Trust}

According to our discussions people often lack the confidence and certitude to share propriety information with other organisations. They often fear that competitors may gain access to proprietary data if they share information such as sales forecasts, proprietary intellectual property or promotional plans with collaborating partners. Nevertheless this kind of real-time sharing of vital operational information is essential if companies want to work together towards a common goal. Establishing trust is potentially the greatest barrier to overcome in collaboration, and it must be established from the outset to allow knowledge sharing. The issue of intellectual property contribution and eventual ownership is something that should be decided on as part of the strategic partnership agreement and should be communicated to all network 
participants prior to beginning any collaborative initiative. Trust is something that cannot be imposed on a network but instead must be 'normed and formed' over time, as with any group dynamic. However, an organisations culture (i.e. values, norms and beliefs) and climate (i.e. policies, practices and procedures) have a significant impact on nurturing trust and therefore knowledge sharing (Cormican and O'Sullivan, 2003b). It is possible to create an organisation that has an appropriate culture to enable knowledge creation, transfer and reuse. This is achieved by developing a culture of openness and dependence, by motivating and engaging people and embedding knowledge management activities in the day to day business processes, internal systems and structures. Employees who are actively encouraged to share ideas, take risks, and initiate change are more inclined to be successful at inter firm collaboration. Thus, it is the leadership of the network nodes that must communicate to the participants a mindset of shared partnership as well as the value-adding joint benefit and long-term future of the network in order to facilitate participants to engage with each other and collaborate within the network.

\subsection{Methods and Tools}

Knowledge management initiatives are just beginning to appear in organisations and there is little research and support systems to guide the development and implementation of such initiatives. Participants in the workshop believe that in many instances there is a tendency to buy generic tools rather than diagnose the core problems and challenges. In other words, off the shelf tools and methods are often bought and deployed in an attempt to address some of the organisation's deficiencies. These tools are often not appropriate to the problem at hand and are often not sufficiently user friendly or person centric. Diagnosing the real problem and understanding the root problem or cause of failure may be more appropriate to effective knowledge transfer. Furthermore, implementing tools that align with existing processes and workflow is imperative. In other words, methods and tools must be context specific and considered to be a means to an end (i.e. an enabler to an existing process) rather than an end in itself (i.e. an additional or separate activity in the organisation). From this analysis, an effective and structured 
approach to knowledge sharing can be designed and deployed. Such methods and tools can enable knowledge transfer to happen quickly and predictably. It is important to remember that a methodology and associated systems for effective and successful knowledge transfer should:

- Address and align with existing business processes not functions

- Be context specific and focus on the user

- Be aligned with organisational goals, strategies and measures

- Help provide information and arguments to decision makers

- Make appropriate use of proven and available management techniques and tools

- Take into consideration the organisations culture and value systems.

\subsection{Resources}

All participants asserted that effective knowledge sharing and transfer demands time, energy and resources. However these resources are often in short supply and most employees do not have sufficient time and support to rethink and redesign their knowledge processes. Organisational resources may be categorised as tangible such as money and equipment, or intangible which would include, time and support. Management demonstrates tangible support for effective knowledge transfer through a specific budget allocation. For example, management can demonstrate their support by providing funding for supporting mechanisms such as face-to-face meetings that allow the network members to 'norm and form'. Time is also cited as an important resource. Employees need sufficient time to capture and transfer critical knowledge. Furthermore time and attention must be paid to redesigning and restructuring internal processes to support effective knowledge transfer.

\subsection{Information Capture and Access}

It is widely accepted that knowledge is generated by selecting and combining information. To do this, the right information must be made available to the individual at the right time and in the right format. In other words, critical information must be captured and leveraged to the point of action and/or decision. The participants of the workshop noted that the barriers to sharing 
information have been dramatically reduced by information communication technologies such as the internet and structured groupware systems. They also noted that these systems often produce too much information that is of marginal value. It seems that there is a lack of a common language between representatives from different organisations and consequently there can be many different interpretations of the same statement. Therefore, information is often misinterpreted between its creation and incorporation. Furthermore, information is often incorrectly formatted in documents and files and people are unable to communicate effectively. People often do not know what information to share, where critical information can be found and how to transfer it to others. Therefore, a common and agreed language and format must be finalised from the outset in order to allow the members to understand each other.

\subsection{Discussion}

Despite the fact that the majority of the participants originated from technological background, the core problems they highlighted were on the 'softer' side of knowledge sharing and integration rather than the technical infrastructure. It seems that the key problems with knowledge sharing lie with the individual and organising the individual in an organisational setting. Consequently, attention must be paid to redesigning and restructuring internal processes to support this new collaborative business environment. Astute changes in the work environment can make substantial improvements in knowledge sharing. Therefore, if organisations wish to either encourage or optimise knowledge sharing they must explore the range of identifying factors. However, the task of managing a climate conducive to sharing is not trivial. Management can influence what the company wants to do and what it can do. By focusing on specific new strategies and measures, the employees can change their motivation and goals, and by generating better resources the company can improve its sharing potential. Successful initiatives require support and backing from key leaders in order to overcome the natural resistance of organisations to change. Inter firm collaboration may demand even greater leadership and support than previous internally focused initiatives. Therefore leaders must focus on the specific, tangible business 
benefits of these efforts, and participants across collaborating organisations must understand and support those benefits. Such foundation building will be critical in overcoming the barriers to inert firm collaboration.

\section{Conclusion}

Progressive organisations are changing their business models on order to compete in dynamic markets. Organisations with specific and complementary competencies are working together in a network in order to design, develop and deploy products and services for mutual gain. To do this they must seamlessly share knowledge, expertise and resources. However reaching end to end synchronisation is not an easy task and organisations are experiencing many knowledge management oriented problems. Specifically they find it difficult to identify relevant information and knowledge and leverage it to the point of action and/or decision. This paper attempts to provide a better understanding of knowledge and knowledge related issues. It examines the key problems with sharing knowledge across organisational boundaries in a collaborative network. An exploratory study was conducted using focused workshop techniques. The aim of the study was to identify and prioritise the current problems and future challenges associated with sharing knowledge across organisations. The findings of this study suggest that the key challenges to effective knowledge transfer are person oriented. Knowledge workers often do not understand the need or rationale for sharing relevant information and knowledge with others. They often feel that knowledge is power and they do not trust others with this power. Many knowledge workers feel that the current methods and tools are inappropriate and unwieldy and they believe that there are insufficient resources in terms of time and money available to effectively restructure internal processes to support effective knowledge transfer. Finally, we found that attention must be paid to manner in which information is captured so that it can be effectively leveraged to the point of decision. In light of this, it seems that more attention must be paid to creating suitable work environments and structures that promote, enable and support effective knowledge transfer. Such systems must add value, be person centric and meet the real needs of the individual and/or team. More specifically, leaders and decision makers should consider 
human aspects such as the organisations culture, climate and value system as well as technical factors such as information technology solutions to facilitate successful knowledge transfer. Developing an effective knowledge management strategy depends on adopting a holistic approach to all aspects of the organisation. This includes people, process as well as technology related issues.

\section{References}

Badaracco, J.L. (1991) The Knowledge Link - How Firms Compete Through Strategic Alliances, Harvard Business Press, Boston.

Balasubramanian, R. and Tiwana, A. (1999) Supporting collaborative process knowledge in new product development teams, Decision Support Systems, 27, 1-2, pp 213-135.

Balconi, M., Breschi, S., Lissoni, F. (2004) Networks of inventors and the role of academia: an exploration of Italian patent data, Research Policy, 33/1, pp. 127145.

Bennett, R. and Gabriel, H. (1999) Organizational factors and knowledge management within large marketing departments: an empirical study, Journal of Knowledge Management, 3, 3, pp 212-225.

Blackler, F. (1995) Knowledge, Knowledge Work and Organizations: An Overview and Interpretation, Organization Studies, 16, 6.

Bohn, R. (1994) Measuring and managing technological knowledge, Sloan Management Review, Fall, pp 61-73.

Brown, J.S., and Duguid, P. (1991) Organizational learning and communities-ofpractice: Toward a unified view of working, learning, and innovation, Organization Science, 2, 1, pp 40-57.

Cormican, K. and O'Sullivan, D. (2004) Groupware Architecture for R\&D Managers. International Journal of Networking and Virtual Organisations, 2, 4, pp. 367-386.

Cormican, K. and O'Sullivan, D. (2003a) A Collaborative Knowledge Management Tool for Product Innovation Management. International Journal of Technology Management, 26, 1, pp 53-67.

Cormican. K and O'Sullivan, D. (2003b) A Scorecard for Supporting Enterprise Knowledge Management. International Journal for Information and Knowledge Management, 2, 3, pp 191-201.

Currall S. C. (2003) Observations and recommendations regarding university 
technology commercialization programs in England and Scotland. Rice University, Houston TX. (Sponsored by Invest-UK)

Davenport, T.H. and Prusak, L. (1998) Working Knowledge: How Organisations Manage What They Know, Harvard Business Press, Boston.

Davenport, T.H., De Long, D.W. and Beers, M.C. (1998) Successful knowledge management projects, Sloan Management Review, Winter, pp 43-57.

Davenport, T.H., Jarvenpaa, S.K. and Beers, M.C. (1996) Improving Knowledge Work Processes. Sloan Management Review, Summer, pp 53-65.

Davies, J., Fensel, D. and Van Harmelen, F. (2003) Towards the Semantic Web: Ontology Driven knowledge management. John Wiley and Sons; Chichester.

de Ruyter, K. (1996) Focus versus nominal group interviews: a comparative analysis, Marketing Intelligence and Planning, 14, 6 pp 44-50.

Dooley L and O'Sullivan D, (2003) Developing a software infrastructure to support systemic innovation through effective management The International Journal of Technological Innovation and Entrepreneurship (Technovation), 23, 8, pp 689-704.

Drucker, P. (1993) Post Capitalist Society, Harper Business, New York.

Finholt, T., (2002) Collaboratories. Annual Review of information science and technology, 36, pp 73-107.

Gibbons, M., Limoges, C., Nowotny, H., Schwartzman, S., Scott, P., and M. Trow (1994). The New Production of Knowledge: the dynamics of science and research in contemporary societies, London: Sage.

Grant, R. (1996) Prospering in dynamically competitive environments:

Organisational capability as knowledge integration, Organization Science, 7, 4, pp 375-387.

Grant, R. (1996) Toward a knowledge based theory of the firm, Strategic Management Journal, 17, pp 109-122.

Grant, R., (1997) The Knowledge-based View of the Firm: Implications for Management Practice, Long Range Planning, 30, 3, pp. 450-454.

Gunasekaran, A. (1999) Agile manufacturing: A framework for research and development, International Journal of Production Economics, 62, 1-2, pp 87105.

Haldin-Herrgard, T. (2000) Difficulties in diffusion of tacit knowledge in organizations, Journal of Intellectual Capital, 1, 4, pp 357-365. 
Harris, J.R. and McKay, J.C. (1996) Optimising product development through pipeline management. In The PDMA Handbook of New Product Development. (Ed, Rosenau, M.D., Griffin, A., Castellion, G.A. and Anschuetz, N.F.) John Wiley and Sons, New York.

Hildreth, P., Kimble, C., Wright, P. (2000) Communities of practice in the distributed international environment, Journal of Knowledge Management, 4, 1, pp 27-38.

Holthouse, D. (1998) Knowledge research issues, California Management Review, 40, 3, pp 277-800.

Hussler, C. and Ronde, P., (2002) Proximity and academic knowledge spillovers: New evidence from the networks of inventors of a French university. European Network on Industrial Policy (EUNIP) Conference 2002, Turku, Finland; Dec 5-7.

Jaffe, A. B., (1989) Real effects of academic research, American Economic Review, 79, pp 697-970.

Johnson, P., Heimann, V., O'Neill, K., (2001) The "wonderland" of virtual teams, Journal of Workplace Learning, 13, 1, pp 24-30.

Jones, P. and Jordan, J. (1998) Knowledge orientations and team effectiveness, International journal of Technology Management, 16, pp 152-161.

Kiesler, S. and Cummings, J., (2002) What do we know about proximity and distance in work groups? In Distributed Work, Hinds, P. and Kiesler, S. (Ed). MIT Press, Cambridge MA.

Knock, N., McQueen, R., and Corner, J. (1997) The Nature of data, information and knowledge exchanges in business processes: Implications for process improvement, The Learning Organization, 4, 2, pp 70-80.

Kreiner, K. (2002) Tacit knowledge management: the role of artefacts. Journal of Knowledge Management, 6, 2 pp 112-123.

Kruat, R., Egido, C. and Galegher, J., (1990) Patterns of contact and communication in scientific research collaboration. In Intellectual Teamwork: Social and technological bases for cooperative work, Galegher J, Kruat R, Egido C, (Ed), Lawrence Erlbaum Publishing; Hillsdale, New Jersey.

Langford, B. E., Schoenfeld G. and Izzo, G. (2002) Nominal grouping sessions vs focus groups. Qualitative Market Research: An International Journal, 5, 1, pp 58-70.

Leonard, D. and Senipser, S. (1998) The role of tacit knowledge in group innovation, California Management Review, 40, 3, pp 112-132.

Mandviwalla, M. and. Khan, S. (1999) Collaborative Object Workspaces 
(COWS): Exploring the integration of collaboration technology, Decision Support Systems, 27, pp 241-254.

McDaniel, C.D. and Gates, R.H. (2000) Contemporary Marketing Research, 4th ed., Southwestern College Publishing, Cincinnati, $\mathrm{OH}$.

McDaniel, C.D. and Gates, R.H. (2001) Marketing Research Essentials, 3rd ed., Southwestern College Publishing, Cincinnati, $\mathrm{OH}$.

Nadler, D.A. and Tushman, M.L. (1999) Organization of the future: Strategic imperatives and core competencies for the 21st century, IEEE Engineering Management Review, 27, pp 96-107.

Nonaka, I. and Takeuchi, H. (1995) The knowledge creating company: how Japanese companies create the dynamics of innovation. Oxford University Press, Oxford.

Nonaka, I., and Konno, (1998) The concept of BA - building a foundation for knowledge creation, California Management Review, 40, 3, pp 40-54.

Oakland, J.S. (2000), Total Quality Management: Text with Cases, Butterworth Heinemann, Boston, MA, pp. 148-9.

Pan, S.L. and Scarbrough, H. (1998) A Socio-Technical View of Knowledge Sharing at Buckman Laboratories, Journal of Knowledge Management, 2, 1 pp 55-66.

Pawar, K. S and Sharifi, S., 2000, Virtual collocations of design teams: coordinating for speed, International Journal of Agile Management Systems, 2, 2, pp 104-113.

Polanyi, M. (1966) The Tacit Dimension, Routledge and Kegan Paul, London.

Porter, M. (1985) Competitive Advantage: Creating and Sustaining Superior Performance New York, Free Press

Prasad, K. and Akhilesh, K.B., (2002) Global virtual teams: what impacts their design and performance, Team Performance Management, 8, 5, pp 102-112.

Quinn, J., Anderson, P. and Finklestein (1996) Managing professional intellect: Making the most of the best, Harvard Business Review, 74, pp 71-80.

Ratcheva, V. and Vyakarnam, S. (2001) Exploring team formation processes in virtual partnerships, Integrated Manufacturing Systems, 12, 7, pp 512-123.

Rayport, J.F. and Sviolka., J.J. (1995) Exploiting the virtual value chain, Harvard Business Review, Nov-Dec.

Richardson, B. (1995) How to administrate the networked organization: tips from the theory and practice of management, The Learning Organization, 2, pp 4-13. 
Ruggles, R. (1998) The state of the notion: Knowledge management in practice, California Management Review, 40, pp 80-89.

Ruggles, R.L. (Ed.) (1997) Knowledge Management Tools, Butterworth Heinenmann, Boston.

Scarbrough, H. and Swan, J. (1999). Cases in Knowledge Management. People Management Series. London: Institute of Personnel Development.

Stewart, T. A. (1997) Intellectual Capital: The New Wealth of Organizations, Doubleday.

Sveiby, K.E. (1997) The New Organizational Wealth: Managing and Measuring Knowledge Based Assets, Berrett-Koehler, San Fransisco.

Tidd, J. (2001) Innovation management in context: environment, organization and performance, International Journal of Management Reviews, 3, 3, pp. 169183.

Ulrich, D. (1998) Intellectual Capital = Competence * Commitment, Sloan Management Review, Winter, pp 15-26.

Venkatraman, N. and Henderson, N. (1998) Real strategies for virtual organizing, Sloan Management Review, Fall, pp 33-48.

Voss, C. A. (2003), Rethinking paradigms of service, International Journal of Operations and Production Management, 23, 1, pp 88-104.

Walters, D. and Buchanan, J. (2001), The new economy, new opportunities and new structures, Management Decision, 39, 10, pp 818-834.

Warkentin, M., Bapna, R., and Sugumaran, V. (2001) E-knowledge networks for inter-organizational collaborative e-business, Logistics Information Management, 14, 1, pp148-163.

Warner, M. and Witzel, M. (2004) Managing in Virtual Organisations; Thompson Learning.

Wenger, E., Communities of Practice: Learning, Meaning and Identity, Cambridge University Press (1998).

West, M.A, Garrod, S, Carletta, J., (1997) Group decision-making and effectiveness: unexplored boundaries, Cooper, C.L., Jackson, S.E, (Eds) Tomorrow's Organizations, Wiley, New York, NY, pp 293-317.

Wiig, K.M. (1995) Knowledge management: Where did it come from and where will it go?, Expert Systems with Applications, 13, pp 1-14.

Wikstrom, S., Normann, R., Anell, B., and Ekvall. G. (1994) Knowledge and 
Value: A New Perspective on Corporate Transformation, Routledge, London.

Wilson, D.A. (1996) Managing knowledge. Butterworth Heinnmann- Oxford.

Wright, D.T. and Burns, N.D., (1998), New organisation structures for global business: an empirical study, International Journal of Operations and Production Management, 18, 9, pp 896- 923.

Zack, M. (1999) Managing codified knowledge, Sloan Management Review, pp 45-58. 